\title{
ArcheoSciences
}

Revue d'archéométrie

33 (suppl.) | 2009

Mémoire du sol, espace des hommes

\section{Application of the OhmMapper resistivity-meter to detect the theatre of Sentinum Roman town by using 3D resistivity model}

M.C. Bottacchi, T. Colonna, F. Mantovani and M. Medri

\section{CpenEdition}

\section{Journals}

Electronic version

URL: https://journals.openedition.org/archeosciences/1673

DOI: 10.4000/archeosciences. 1673

ISBN: 978-2-7535-1599-4

ISSN: $2104-3728$

Publisher

Presses universitaires de Rennes

\section{Printed version}

Date of publication: 30 October 2009

Number of pages: $267-269$

ISBN: 978-2-7535-0943-6

ISSN: $1960-1360$

\section{Electronic reference}

M.C. Bottacchi, T. Colonna, F. Mantovani and M. Medri, "Application of the OhmMapper resistivitymeter to detect the theatre of Sentinum Roman town by using 3D resistivity model", ArcheoSciences [Online], 33 (suppl.) | 2009, Online since 30 October 2011, connection on 01 February 2022. URL: http://journals.openedition.org/archeosciences/1673; DOI: https://doi.org/10.4000/archeosciences. 1673 


\title{
Application of the OhmMapper resistivity-meter to detect the theatre of Sentinum Roman town by using $3 \mathrm{D}$ resistivity model
}

\author{
M. C. Bottacchi*, T. Colonna*, F. Mantovani ${ }^{* *}$ and M. Medri ${ }^{* * *}$
}

Key words: Resistivity, OhmMapper, Capacitive-coupled system, Sentinum, 3D inversion resistivity models.

\section{INTRODUCTION}

The application of geophysical methods to investigate the near-surface soil layers containing anthropic products has been recognized as an important element of archaeological research by the international community.(Clark, 1996). Geophysics can delineate quickly the presence of archaeological structures without invasive stratigraphic excavation. In particular, resistivity surveying can be used to understand the geometry and depth of the anthropic element buried in the subsoil, due to the different resistivity properties between potential archaeological targets and the surrounding environment (Loke, 2004).

Geoelectrical data are traditionally acquired with a galvanically-coupled resistivity system. Placing electrodes in the soil is the greatest practical difficulty for it is time consuming and prevents rapid investigation, especially in the case of a three-dimensional survey. This problem can be avoided using the new OhmMapper (Geometrics Inc.) capacitive-coupled resistivity system designed to be pulled along the ground as a streamer that realizes an almost continuous profile.
The regular urban nature of the settlement of Sentinum (Sassoferrato municipality, Ancona, Italy), typical of cities planned by the Emperor Augustus (1st century BC-1st century $\mathrm{AD}$ ), has been confirmed by magnetometric investigations carried out some years ago (Bottacchi and Hay, 2008). Nevertheless, one paradigm of Roman cities, the theatre, is missing from this city plan obtained by means of geophysical prospection.

The ultimate objective of this study is to detect the theatre of Sentinum using a 3D resistivity model created by OhmMapper.

\section{SYSTEM DESCRIPTION}

The operating principles are simple: an alternating current (AC) is capacitively coupled with the earth at a particular frequency $(16.5 \mathrm{kHz})$ by an alternating voltage applied to a transmitting dipole; the resulting AC voltage coupled to a receiver dipole is then measured. The transmitter and receiver antennas are deployed in a dipole-dipole configu-

\footnotetext{
* Centro di GeoTecnologie, Università degli Studi di Siena, Via Vetri Vecchi 34, 25057 San Giovanni Valdarno, Arezzo, Italy. (bottacchi@unisi.it) (colonna3@unisi.it)

** Dipartimento di Fisica, Università di Ferrara, Via Saragat 1, 44100 Ferrara, Italy. (mantovani@fe.infn.it)

*** Dipartimento di Studi Storico-Artistici, Archeologici e sulla Conservazione, Università degli Studi Roma Tre, P.zza della Repubblica 10, 00185 Roma, Italy. (mmedri@uniroma3.it)
} 


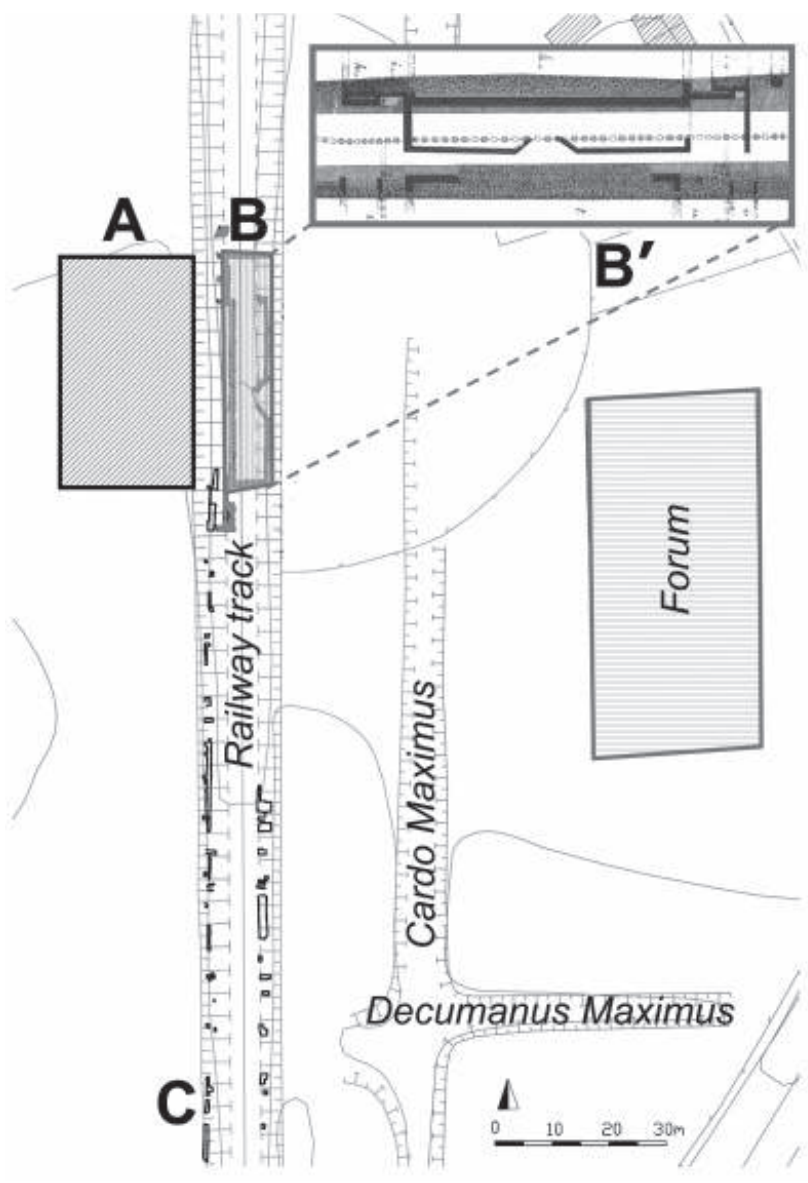

Figure 1: Localization map of the survey area (A), monumental foundations discovered in 1890 (B and B' as a detail), archaeological features visible on both sides of the railway track section (C) and public areas (Forum, Cardo Maximus and Decumanus Maximus).

ration, that is sensitive to lateral changes of resistivity and can delineate vertical structures, such as cavities and walls. Implementation of this array for acquisition of high density data (one reading per second in continuous survey mode) allows high resolution two- and three-dimensional (2D and 3D) resistivity models, also in the complex subsurface of multi-stratigraphic archaeological sites, such as the Roman town of Sentinum.

The most common practice for a three-dimensional resistivity survey is to record 3D resistivity variation of the subsurface with dense parallel 2D lines (Papadopoulos et al., 2006). With the OhmMapper mapped-survey mode it is possible to acquire complete sets of 3D measurements faster than with a galvanic multi-channel automated resistivitymeter(Aspinall et al., 2005) because there is no finite number of electrodes to move. The collected data are ready to be exported for 3D inversion software.

\section{RESISTIVITY SURVEY IN THE ROMAN TOWN OF SENTINUM}

Sentinum is a complex multi-stratigraphic site: from its foundation in the 1st century $\mathrm{BC}$ to its abandonment because of the Gothic raids in the 5th century, the Roman town went through a number of different building stages. The different periods of occupation of the town can be seen readily in the two sections generated by the excavation for the construction of a railway track between Fabriano (Ancona) and Urbino in the 19th century. Archaeological excavations are hardly suitable for tracing the urban layout of an archaeological site (about 15 hectares) in a short period of time, considering that in the years since 1972 less than $10 \%$ of all the archaeological structures within the town walls have been uncovered.

In order to detect the Roman theatre structure, we carried out a resistivity OhmMapper archaeological survey in a restricted area of the Roman town of Sentinum suggested by the archaeological director. The investigated area to the west of the railway track is not far from Roman public areas and is next to some monumental foundations discovered in 1890 during the construction of the railway track; moreover, the magnetometric data acquired in this area do not give a clear picture.

In the chosen area a survey was carried out along parallel lines set close to one another in order to intercept the hypothesized buried foundations of the theatre: several resistivity maps were created at different depths, from a few centimetres below ground surface to the Late Pleistocene Terrace Flood Deposits, which are untouched by anthropic activities. To verify OhmMapper data quality, selected lines of the survey grid were repeated with a traditional galvanic resistivity-meter. Moreover, a comparison was made between resistivity signals and archaeological features from both sides of the railway track section to define the range of resistivity values characterizing Roman foundations.

This multi-method approach permits a check of data from several independent measurements and broadens the range of geometrical and physical information available for interpretation.

\section{Conclusions}

Data acquired by the OhmMapper survey in the Roman town of Sentinum were used to create a three-dimensional inversion model of the subsurface. The performance of the new OhmMapper resistivity-meter for realizing 3D resistivity survey in archaeological contexts proved to be excellent. 
Figure 2: Results and archaeological interpretation of the OhmMapper Resistivity survey. Both in the resistivity sections (R1; R2) and in the resistivity map it is possible to detect high resistivity features that could be interpreted as monumental foundations, consistent with the characteristic of a Roman theatre.

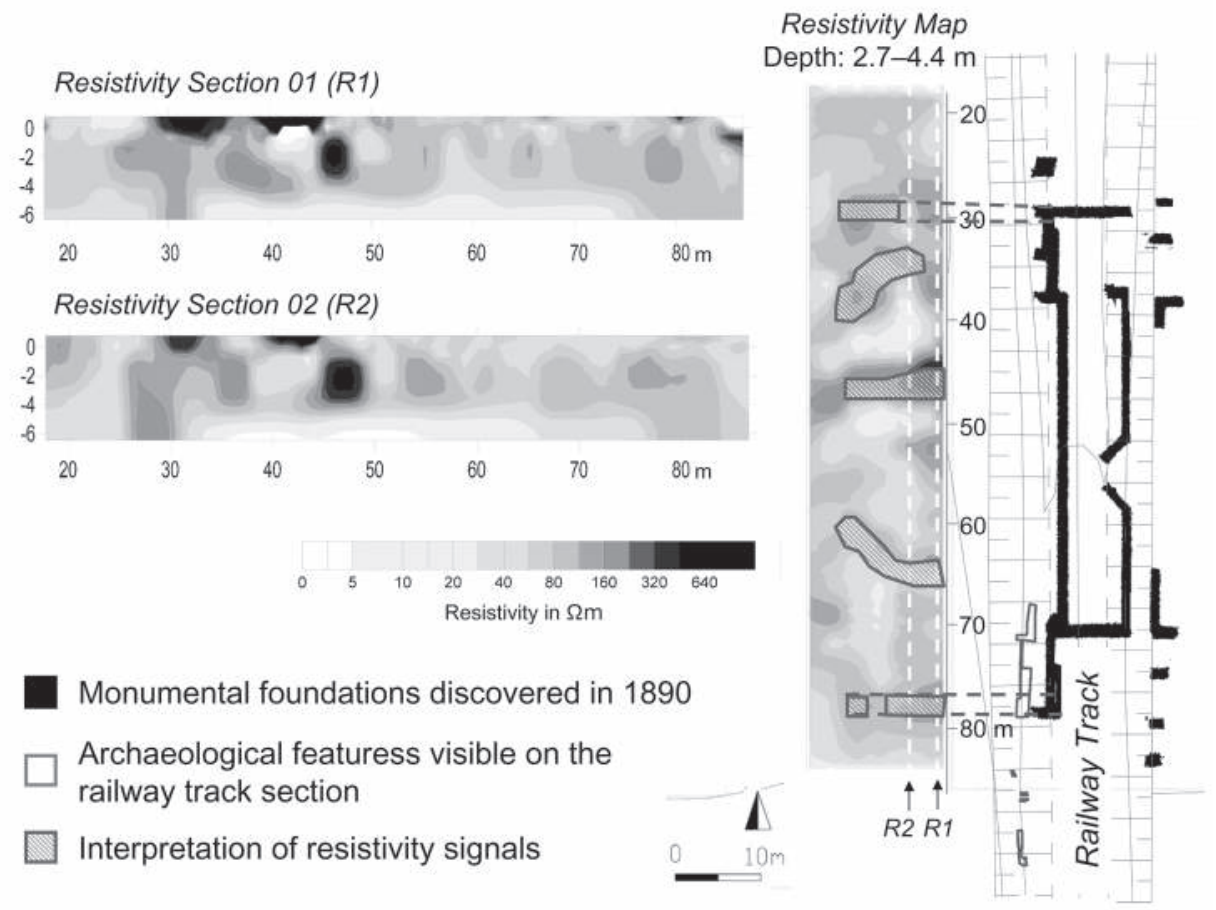

Resistivity Map

epth: $2.7-4.4 \mathrm{~m}$

Resistivity Section 01 (R1)

Resistivity Section 02 (R2)

Monumental foundations discovered in 1890

Archaeological featuress visible on the railway track section

Interpretation of resistivity signals 